\title{
Procedural coordination and offshored software tasks: Lessons from two case studies
}

Article in Information \& Management · March 2007

DOI: 10.1016/j.im.2006.12.001 · Source: DBLP

\section{CITATIONS}

48

1 author:

\section{Rajesh Mirani}

University of Baltimore

28 PUBLICATIONS 550 CITATIONS

SEE PROFILE
READS

64

Some of the authors of this publication are also working on these related projects:

Project (To be Decided) View project 
Provided for non-commercial research and educational use only. Not for reproduction or distribution or commercial use.

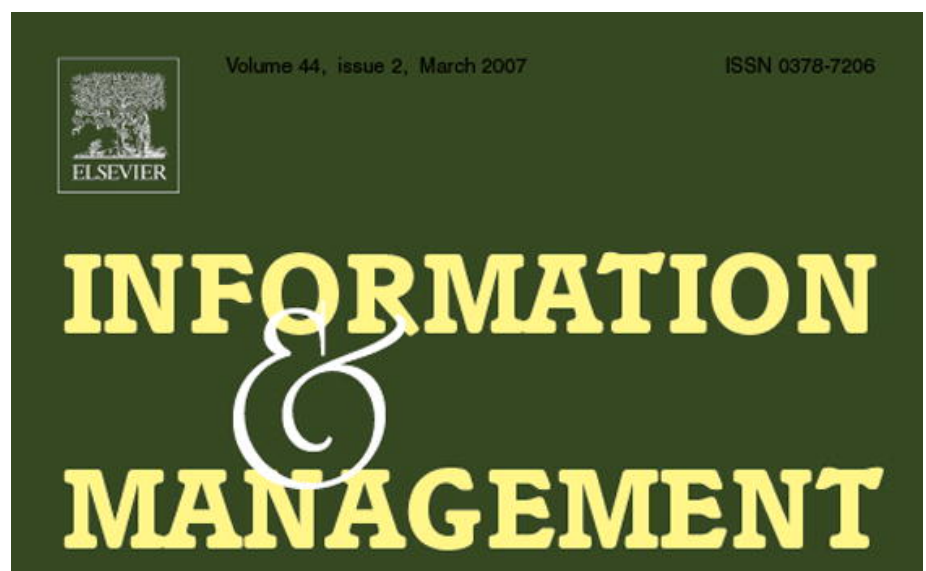

THE INTERNATIONAL JOURNAL OF INFORMATION SYSTEMS APPLICATIONS

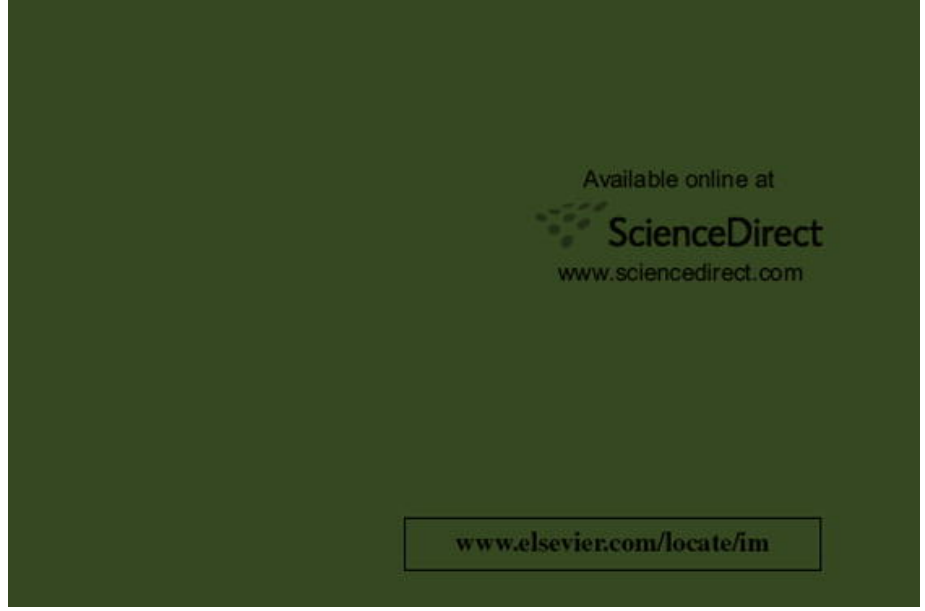

This article was originally published in a journal published by Elsevier, and the attached copy is provided by Elsevier for the author's benefit and for the benefit of the author's institution, for non-commercial research and educational use including without limitation use in instruction at your institution, sending it to specific colleagues that you know, and providing a copy to your institution's administrator.

All other uses, reproduction and distribution, including without limitation commercial reprints, selling or licensing copies or access,

or posting on open internet sites, your personal or institution's website or repository, are prohibited. For exceptions, permission may be sought for such use through Elsevier's permissions site at: 


\title{
Procedural coordination and offshored software tasks: Lessons from two case studies
}

\author{
Rajesh Mirani* \\ Merrick School of Business, University of Baltimore, 11 W. Mt. Royal Avenue, Baltimore, MD 21201, United States
}

Available online 16 January 2007

\begin{abstract}
This paper presents two case studies of offshored software tasks. The success of such tasks is critically dependent on managing an inherent interdependence between onshore and offshore teams. In one case study, both teams belong to the vendor organization, while in the other they are affiliated respectively with client and vendor. It is shown that that interdependence is best addressed through procedural coordination, which entails two complementary strategies. The first consists of carefully specifying and partitioning tasks, and the second of implementing integration mechanisms to bridge communication gaps. Despite contextual differences, the two case studies offer common lessons.
\end{abstract}

(C) 2006 Elsevier B.V. All rights reserved.

Keywords: Offshoring; Outsourcing; Case study; Procedural coordination; Task partitioning; Integration mechanisms

\section{Introduction}

Software related tasks are highly interdependent by their very nature [10]. Systems development, infrastructure activities, and the provision of software services are all knowledge intensive tasks, characterized by sequential and reciprocal interdependence between individual team members [25,17]. A high degree of interdependence is known to create communication gaps and hamper team productivity and effectiveness. Offshored software projects often necessitate globally dispersed teams, either affiliated with a common vendor organization or separate client and vendor organizations. Such projects are typically labor intensive, and critically dependent on frequent, intense client-vendor interactions in which the vendor continually strives to

\footnotetext{
* Tel.: +1 4108375261.

E-mail address: rmirani@ubalt.edu.
}

grasp the client's business processes [6]. The predominant context of interdependence is therefore intergroup and/or inter-organizational, depending on the affiliations of the teams. The detrimental effects of sequential and reciprocal interdependence in an interorganizational context are best offset by employing a combination of approaches, including lateral integration (e.g., liaisons), property rights sharing, hierarchies, and programming or closely specifying the task [14].

Such mitigation approaches implicitly assume a mutual alignment of interests, and focus instead on overcoming the difficulties of aligning the actions of two independent organizations. They are therefore generically referred to as coordination mechanisms, to distinguish them from incentive- or reward-oriented approaches designed to induce cooperation [15]. Further, a distinction has been proposed between contractual coordination and procedural coordination [27]. In this dichotomous classification, contractual coordination, or the mutual exchange of rights, pertains to issues of setup 
and outcome measurement. This institutional perspective addresses the activities associated with formal interorganizational agreements and their enforcement. Setup and measurement activities tend to be sporadic in nature and occur at the level of senior executives and corporate lawyers. Procedural coordination, or the mutual exchange of information, governs the implementation of day-to-day cooperative and collaborative activities. This process-oriented perspective relates to issues that are fluid and ongoing in character, not usually etched into contracts, and addressed at the level of operational staff and managers. An analogous dichotomy mirroring this duality of coordination approaches has been mentioned specifically in the information systems outsourcing context, where contractual coordination has been termed as the promissory contract between client and vendor, and procedural coordination as the psychological contract [23].

This paper presents two case studies to highlight the critical, enabling role of procedural coordination in facilitating successful interchanges between onshore and offshore teams for software related tasks. Procedural coordination takes on special importance with such inherently uncertain and knowledge intensive collaborative tasks because the specific mechanisms employed need to be flexible in order to adapt to intricately evolving task and relationship attributes. For this reason, it has been suggested that contractual agreements between collaborative partner organizations should steer clear of providing detailed stipulations of the precise steps, measures, and procedures that will be followed during implementation [16]. Doing so provides both parties with the requisite flexibility and managerial autonomy that will increase the likelihood of successful interactions. However, as the case studies will demonstrate, this also catapults the role of procedural coordination to a higher level, in terms of its ability to almost exclusively influence outcomes.

Unlike contractual coordination, which applies only in an inter-organizational context, the key premise of procedural coordination is extensible to an inter-group context within a given organization. This is because the underlying assumption of cooperation and the resultant emphasis shift to operational-level collaboration and information exchange are as applicable to teams working together as they are to independent organizations pursuing a common goal. The two case studies confirm this. While both recount interactions between geographically dispersed teams, one is set in an interorganizational context and the other in an intraorganizational context. Their analysis will show that the lessons they provide are common, applicable both to globally separated client-vendor teams as well as dispersed teams belonging to a common vendor organization.

The remainder of this paper is organized as follows. First, the conceptual foundations of procedural coordination are presented from the inter-organizational literature, including a review of its role in outsourcing and offshoring. This is followed by the two offshoring case studies. Finally, the case studies are analyzed and implications discussed.

\section{Conceptual foundations of procedural coordination}

There are two major strategies entailed in procedural coordination [26]. The first of these two strategies entails specifying tasks across organizational or team boundaries, in order to minimize potential problemsolving exchanges. Doing so calls for analyzing the tasks, assessing any interdependency hierarchies among sub-tasks, and accordingly partitioning them among the organizations or teams. The second strategy consists of applying learning-oriented integrative mechanisms across organizational or team boundaries, with a view to bridging communication gaps and minimizing the overall cost of problem-solving exchanges. Integrative mechanisms include formal and informal structures, such as channels and liaison roles, as well as mutual arrangements and commitments put in place to successfully complete the tasks at hand. Together, task specification/partitioning and integrative mechanisms comprise complementary strategies for effective procedural coordination.

Techniques for partitioning coding processes for software programs are well documented in the literature (e.g., [8]). However, the term partitioning as used here refers to the larger context of planning, managing, and executing all task-related activities. Specifying and partitioning tasks lowers interdependence and creates loose coupling among the resulting sub-tasks, which in turn fosters greater inter-organizational or inter-team efficiency. A broader study on software design and coding projects examined the impact of task interdependence on development productivity for cross-functional teams [3]. Low task interdependence was defined as the design and coding of stand-alone modules, and high task interdependence characterized as the need for greater collaboration. The study found that in general development productivity was higher when task interdependence was low, supporting the case for loosely coupled or independent development tasks. 
A case for task specification and partitioning was also made in a study that examined various combinations of task complexity, contestability, and asset specificity, each ranging from low to high [13]. Seven such combinations were examined. In particular, projects with low complexity, high contestability, and low asset specificity were deemed as being ideal for outsourcing because of the potential for lowering production costs while keeping bargaining costs and opportunism to a minimum. When complexity was increased while keeping specificity low and contestability high, opportunism remained low but bargaining costs went up. This was due to the inherent difficulty of comparing ex post performance to ex ante expectations, and the potential for disagreements. For this combination of task attributes, the implication was that an appropriate initial strategy would entail making the process less complex by disaggregating or breaking up tasks.

Team effectiveness is even more adversely affected when task interdependence is accompanied by geographic dispersion. This was demonstrated in a study of software development virtual work teams at an international consulting firm [10]. Teams were characterized by varying degrees of geographic dispersion of members. Work conducted ranged across the spectrum, including gathering user requirements, component/module design and development, testing, documentation, deployment, testing, and maintenance. It was found that teams with greater geographic dispersion tended to have less effective performance than those with collocated members. Geographic dispersion resulted in less effective work processes, which in turn reduced team performance. The implication was that managers of geographically dispersed teams should pay careful attention to building and maintaining social systems that would keep team members connected to each other.

Such social systems and other integration mechanisms offer rich learning opportunities under conditions of high interdependence. By facilitating better information flows, they enhance inter-group or inter-organizational interactions, increasing the likelihood of success in joint activities [18]. In a structuration theory of interorganizational coordination, integration mechanisms such as informal linkages, liaisons, and boundary spanners were clubbed together under the umbrella term "microcoordination structures," to distinguish them from firm-level structures and more abstract notions [2]. Informal linkages include information exchanges between organizational or team representatives, in person, via meetings, or through communication technologies. Liaisons and boundary spanners are more formalized versions of such linkages. These roles, typically affiliated with one organization, serve to influence the actions of the other in a dyadic relationship. Formal coordinators, steering committees, boards, and task forces represent institutionalized versions of integrative linkages.

\subsection{Key role of informal dynamics, and task as moderator}

Among all integration mechanisms, the role of informal linkages is particularly informative, and especially in its interactions with task attributes. In the research study on task interdependence mentioned earlier, it was additionally postulated that success in software design and programming would be a function of the fit between task interdependence, goal conflict, and coordination strategy [3]. Together, these factors represented organizational design configurations that were hypothesized to impact the outcome dimensions of team productivity and process satisfaction. Coordination strategies were dichotomized into organic and mechanistic. Organic coordination strategies were defined as those characterized by informal, cooperative, and decentralized techniques. Mechanistic strategies were said to employ formal, controlling, and centralized approaches. While low task independence was in general found to be more beneficial, it was found that productivity under high task interdependence could be significantly enhanced by employing organic coordination techniques. Process satisfaction was also higher in the presence of organic coordination.

Similar findings were obtained in an independently conducted field study of hospital-based software development groups [21]. This study explored the influence of decision and control structures on group effectiveness, and the moderating role of task complexity in this relationship. Decision-making structures were dichotomized as mechanistic or organic, and control structures as bureaucratic or interpersonal. It was found that high task complexity combined with mechanistic structures actually reduced effectiveness, while organic structures combined with higher task complexity enhanced effectiveness. The more organic the structure, the greater was the effectiveness. Likewise, bureaucratic structures were found to be more appropriate for tasks of low complexity, and interpersonal structures for tasks of high complexity.

A study of software development teams examined the influence of team attributes such as coordination, communication, balance of member contributions, mutual support, effort, and cohesion, on measures of 
team efficiency and effectiveness [19]. These team attributes were found to promote schedule and budget adherence as well as enhance quality related measures. The impact on schedule and budget adherence was particularly stronger when tasks entailed novelty, complexity, and uncertainty. The implication was that the extent of collaborative behavior within teams should be tuned up or down to be in consonance with ongoing task attributes, when adherence to schedules and budgets is the desired goal.

Studies in R\&D task contexts mirror the above findings. One such study focused on R\&D collaboration between clients and vendors and examined the moderating influence of task-related attributes in the impact of trust-based governance on outsourcing relationship performance [7]. It found that trust-based partnerships that included informal commitments, expectations, and agreements between clients and vendors resulted in more effective relationships. The impact of trust on partnership effectiveness was even stronger when the client was highly skilled at understanding the outsourced tasks, when task completion required skills that were readily taught, and when work done at the vendor's end was in parallel with other work done at the client's end. In other words, the effectiveness of integrative mechanisms was greater when accompanied by fully understood tasks that were easily specified and horizontally partitioned between clients and vendors.

Another study of R\&D groups tested the similar premise that group communication structure needs to be in accordance with task requirements in order to ensure high performance [20]. Specifically, non-routine and unstructured tasks were hypothesized to necessitate more information processing, in terms of information communicated within the group, within the $R \& D$ function, within the broader organization, and outside the company. Information processing by itself was found to enhance both schedule-budget performance as well as project quality. However, the impact of information processing on schedule-budget performance declined significantly over time. In addition, the fit of information processing with non-routine tasks successfully predicted project quality.

\section{Case studies}

The discussion above strongly affirms the critical roles of the two elements of procedural coordination, task specification/partitioning and integrative mechanisms, in both inter-group and inter-organizational contexts. An added inference is that success in both contexts is influenced by the fit achieved between the partitioned tasks and the integration mechanisms employed. The two case studies that follow illustrate both points in these respective contexts, as manifested in the domain of offshored software tasks. ${ }^{1}$ The first case study narrates the experiences of a telecommunications carrier in relation to offshored applications development and maintenance, with an emphasis on the dynamics between the vendor's onshore and offshore groups. The second describes the interactions of a financial/economic news and information provider with successive vendors, for offshored tasks such as document conversion, knowledge management, as well as application development and enhancement. Each case is presented in two sections - an initial section comprising of the key case facts, followed by a second section that discusses the coordination mechanisms employed and case outcomes.

\subsection{Case study 1-applications development and maintenance for Telecon}

Telecon is a publicly held incumbent local exchange carrier (ILEC) and a Fortune 500 corporation that has traditionally served the residential and commercial needs of a region comprising several states. It also maintains a strong presence in Latin America. With current annual sales of more than US\$20 billion, its domestic offerings include voice, data, and video services, and recently, cellular networks.

The vendor, Prospera, is a leading global provider of services related to business consulting and technology management, with big clients in various industry sectors as well as government. Comprising of more than 100,000 employees worldwide, Prospera's latest annual revenue figures exceed US\$ 15 billion. In the arena of outsourcing, Prospera has historically offered its clients services related to applications outsourcing, business process outsourcing, and infrastructure outsourcing.

This case study describes the transition of production support (maintenance) activities for Telecon's applications to Prospera's offshore site. Prior to this transition, Telecon had successfully outsourced the design, development, and support of its applications to Prospera's onshore site for a number of years.

Telecon and Prospera first struck an applications development and maintenance outsourcing deal worth US\$ 3 billion in 1998. This deal provided Telecon with

\footnotetext{
${ }^{1}$ The identities of the key organizations in both case studies have been disguised, and other descriptive statistics and facts carefully distorted, to maintain confidentiality yet preserve the essence of the cases.
} 
an opportunity to drastically cut information technology costs, as a counterweight to huge investments in new infrastructure to meet an existing explosive demand for its services. Prospera was assigned full responsibility for front-end applications such as marketing and customer care, and back-end applications such as finance and billing. This outsourcing initiative was immensely successful.

After the dot com bust of 2000, pressures mounted on telecom carriers to recover from sunken investments in excess capacities. With a view to aggressively controlling costs, Telecon and Prospera agreed in late 2001 to expand and extend the outsourcing contract to 2007. The vendor would take on additional applications and projects, including Web services, representing Telecon's business commitments in new directions. Telecon's expectation was that Prospera's involvement would not only cut costs but also result in faster turnaround times. This would translate into shorter cycle times for Telecon's nascent initiatives, and therefore a speedier business transformation and recovery from its economic slump.

In setting up this expanded contract, Prospera recommended moving out all enhancement and maintenance work to its captive "delivery center" in India, given that the highest cost components of applications were in production support. With its stable communications infrastructure, highly qualified workforce, and low wages, India was the preferred offshoring location for about half of the Fortune 500 companies. From there, Prospera's offshore personnel would continue to provide sustained levels of quality and service levels to Telecon at vastly reduced costs. The resulting cost savings, expected to be huge, would be passed on to the client.

Given the attendant risks for an effort of such magnitude, it was agreed that a small-scale pilot venture was needed prior to a full-blown offshoring undertaking. A 5-month pilot was therefore designed, and initiated in April 2003. No disastrous events or critical failures were observed during this period, and both parties therefore stepped up to declare the pilot an unqualified success.

Following the successful pilot, a decision was made to take the plunge and quickly ramp up the pilot to fullblown offshoring. Over the next 4.5 years, the maintenance and enhancement of large chunks of the applications portfolio would be offshored to Prospera's India-based center in successive stages. Each stage would entail the shift of hundreds, even thousands, of applications in production, from various Telecon business units, and representing disparate technologies. It was announced that up to half of Telecon's applications work would be gradually moved offshore through the year 2007, amounting to almost a thousand personnel positions. The cumulative cost savings over this multiyear period were estimated at approximately US\$ 275 million, worth at least half of Telecon's projected technology budgets for those years.

The full-blown offshoring effort, however, quickly proved itself to be much more difficult than expected. Coordination failures between the onshore and offshore Prospera caused a communications breakdown, resulting in Prospera's inability to keep up the levels of support stipulated in its agreement with Telecon. The net result was a failed offshoring effort, from which both client and vendor are still trying to recover.

\subsection{Coordination mechanisms and outcomes in the Telecon case}

The three distinct phases in the Telecon case will now be examined in closer detail, particularly in how the use of task specification/partitioning techniques and integrative mechanisms relate to the outcomes in each phase. A clear connection between the coordination mechanisms employed and the success or failure of each phase will be established, with organizational context serving as the background for the discussion. This will help explain how the client and vendor organizations in this case turned an enormously successful outsourcing project into a failed offshoring endeavor.

\subsubsection{Onshore outsourcing}

Both task specification/partitioning and integrative mechanisms were employed with success in the onshore outsourcing phase for Telecon. The former technique was evident in Prospera's use of a home-grown analytical planning technique called "application constellations." This technique categorizes client applications into groups by one or several criteria, including types of users, common elements, technical interdependencies, common databases, common skills, development techniques, or business importance. Once classified in this way, application groups are then evaluated separately against alternative sourcing models, using criteria such as appropriateness, feasibility, criticality, and strategic value.

In addition, an expectation that Telecon built into its contract with Prospera (and carried forward into subsequent contracts) was that the vendor would establish disciplined software processes corresponding to at least Level 4 of the five-level Capability Maturity Model. 
Higher levels correspond to an increasing shift of attention, away from technical issues, towards organizational and managerial issues. Level 4 is said to have been achieved when detailed measures of the software process and product quality are collected, and when both are quantitatively understood and controlled. Level 5, which is the highest level, emphasizes continuous process improvement enabled through quantitative feedback and from piloting innovative ideas and technologies, leading to optimization.

Integration mechanisms were also amply in evidence. About 900 Telecon employees were permanently transferred to the vendor as part of the initial contract. When the onshore outsourcing contract was extended to 2007, another 300 Telecon employees became Prospera employees. Telecon setup a multi-tier internal organizational structure to handle the intricacies expected from its ongoing interactions with Prospera, and to monitor and evaluate the vendor's performance.

The onshore outsourcing phase was a success. In the very first year of the contract, major improvements in meeting internal time and budget goals were accompanied by a marked rise in project completion rates by a ratio of about one-third. In addition to dramatically reducing development and support costs, Prospera's industry expertise and development skills served to provide Telecon with cutting edge applications and solutions. For instance, a wireless operations support system designed by Prospera for Telecon's service technicians won recognition at a leading annual industry exhibition of communications service providers.

\subsubsection{Pilot offshoring}

For the pilot phase, both task specification/partitioning and integration mechanisms were once again employed. With respect to tasks, a formal process was jointly initiated to carefully identify applications suitable for the pilot effort, using criteria such as number of personnel needed, complexity, stability, and user impact. This process resulted in the identification of three applications, and 17 development and support personnel for these applications. Each application was affiliated with a different business unit of Telecon, but all three applications were back-office in nature, and Prospera had played major roles in the original design of each. One application represented a workflow management system, the second a construction-oriented project management system, and the third a management accounting system. All had been in production for a while and therefore considered fairly stable. The scope of the pilot included mostly maintenance work oriented towards fixing bugs, as well as some ongoing feature enhancements.

Integration mechanisms put in place by Prospera for the pilot phase consisted of dedicated offshore staff teams for each earmarked application. To ensure full and effective knowledge transfer of the business and technological contexts, successive offshore application teams spent several weeks or months at Prospera's onshore client support site, getting up to speed on the organizational roles of the applications, their intricacies, and their typical support tasks. Given the inherently highly structured nature of post-production tasks and that a core strength of Prospera was business process consulting, both client and vendor expected that the transfer of business- and technical-domain knowledge from the onshore support personnel to the new offshore staff would pose no major problems. Prospera intended to apply its expertise to ensure that any transition issues from onshore to offshore would remain totally transparent to Telecon's business units.

The outcome of the pilot phase was a mixed success. Mid-way through the 5-month trial period, Telecon experienced an escalation in internal and external pressures to lower its technology expenditures. These pressures caused a shift in its priorities, and a virtual abandonment of the original pilot goal, which was a rigorous, unbiased review of resources needed for offshoring. While the vendor continued to collect some data in this regard, Telecon's new stance clearly conveyed that there was no need for a formal costsbenefits analysis. Gradually, the pilot took on the role of a proof-of-concept, by which the effort would be deemed successful as long as no dramatic failures occurred. The client also exhibited a new found tendency to dismiss any problems and issues that surfaced, instead of urging the vendor to probe deeper for underlying causes. In turn, Prospera's fear of losing a client to rival vendors engendered a propensity to go along with Telecon's assertion that the objectives of the pilot had been fully met.

\subsubsection{Full-blown offshoring}

Coordination techniques employed for the fullblown offshoring phase comprised almost solely of integration mechanisms. Scant attention was paid to the specification and distribution of tasks. This was unusual, as Prospera did have a "global delivery model" which it had successfully employed for its other offshoring clients. One key aspect of this model provided the vendor the ability to slice and dice large projects into smaller, loosely coupled tasks, using industry practices. These tasks could then be distributed 
to its various global locations for completion. Another aspect of this model enabled Prospera to seamlessly transfer tasks among its various global sites, in order to cope with contingencies and specialty work, and to implement checks and balances related to quality control. This was supported through the use of shared processes and established metrics for quality assurance.

This global delivery model, however, was not actually applied in Telecon's case. For achieving onshore-offshore coordination, integration techniques as outlined in the following paragraph were deemed sufficient, given the logic that (a) the largely back-office types of application functionalities represented welldefined tasks performed on standardized business processes, (b) the applications were reasonably welldocumented, and (c) production support was supposed to be inherently well-structured.

The internal organizational structure setup by Prospera for the oversight of Telecon's production support followed a hybrid offshoring model. A small onshore group would be staffed by personnel whose knowledge of Telecon's business and application context would make them the linchpins of the transition effort. These included application architects and key members of the original support staff. Their new roles would be as liaisons or interfaces with their offshore counterparts, who would take over the actual maintenance and enhancement work and operate in application- or project-oriented teams. As with the pilot phase, representatives of Prospera's new offshore application support teams would first visit its onshore site, to gather the business context and application domain knowledge that they would subsequently share back with their teams. All other Prospera employees originally associated with the Telecon applications were either laid off or reassigned to other internal roles.

Despite the liaison-based integration mechanisms put in place by Prospera, the full-blown offshoring effort quickly ran into major problems. The level of detail contained in application documentation was insufficient to sustain the requisite transfer of business and application knowledge to the offshore staff. In particular, operational-level nuances for individual applications represented essential knowledge never formally captured as documentation. Their only records were the procedural skills acquired by the original application architects and support staff, honed through extensive support experience. Occasional ex post facto annotations in the documentation hinted at these subtleties, but their fragmented and unstructured nature suggested that they were intended more as memory jogs than shareable knowledge. Further, their intensity varied from one application to another as well as within applications. A lack of consistency meant that the offshore teams could not discern meaningful patterns in missing documentation. As more maintenance work continued to shift offshore, documentation gaps and incomplete fillers created unexpected issues. Seemingly straightforward "fixes" often went unresolved for long periods of time, despite the skills and best efforts of the offshore staff. For example, writing a simple SQL-oriented enhancement would turn out to necessitate indexing tasks, but only if certain business and application conditions were true. No details on either the indexing tasks or the necessary preconditions were recorded anywhere. Such poorly understood intricacies led to repeated onshore-offshore interactions whose frequency and intensity were considerably more than what had been planned for. Offshore productivity visibly slackened as a result.

Prospera's compensating response to the offshore staff's productivity loss was to vastly increase the workload of the thin onshore group, in order to ensure conformance with the minimum service support levels stipulated in its maintenance contract with Telecon. Higher workload, coupled with uncertainty about their own future in the organization, caused a decline of morale among onshore staff, and a significant turnover of highly experienced employees. They were replaced by second string personnel whose troubleshooting interactions with the offshore staff did not quite yield the same quality of resolutions. As a result, productivity and responsiveness at both ends declined further. Amid all this, Prospera and Telecon issued the announcement that all Telecon applications - without exception - were now "in scope" for offshoring. No existing application was to be supported onshore any longer.

A concurrent attrition problem plagued the offshore end. Team representatives who returned home after brief onshore stints were supposed to disburse the contextual knowledge they had gathered to their team members, since their role was to serve as primary conduits for the flow of application and business domain knowledge to the offshore site. Their recent overseas "experience," however, provided them with a differentiated edge in the competitive local technology market filled with fresh college graduates. Large numbers of returnees were poached by rival vendors for $15-20 \%$ higher salaries on average, with lucrative promises of leadership roles in cutting-edge design and development projects, often immediately upon their return. The attrition rate was estimated to be as high as $45 \%$, and it left the offshore teams rudderless. 
Communication between the onshore and offshore ends had effectively broken down, wreaking havoc with Prospera's hybrid offshoring model. The silver lining was that the client's application costs had dropped somewhat. However, Prospera's inability to keep up with the levels of support in its commitments to Telecon often caused nonperformance penalty clauses to kick in, resulting in frequent client-levied fines.

Prospera's response to the failure of the hybrid offshoring model was to reorganize its remaining offshore and onshore information technology personnel into functional pools. Vertical teams that previously had been responsible for the total support of specific applications were replaced by horizontal, cross-application pools of personnel specializing in distinct support activities such as coding, configuration, testing and quality assurance, etc. Prospera's rationale was that anchoring individuals to support roles rather than to applications or teams would provide some continuity for them in the face of high turnover rates at both sites. However, the reorganization engendered its own unique issues. In the prior structure all support activities pertaining to a specific application were addressed by a single team. Under the new structure, their responsibility was now scattered across the reorganized personnel pools, such that every pool was supposed to play a role in addressing most major support tasks. This gave rise to a culture that shunned ownership of issues, as evidenced by increasing finger-pointing and passing the buck. Unresolved issues proliferated, and they were nobody's responsibility in particular.

In response to this latest fiasco, Prospera is now actively considering all possible options. These include scaling back the extent of offshored work, disengaging from the client, as well as returning to the original application team structure with some changes. For future clients, Prospera is considering the offshoring of entire application life cycles, including requirements analysis, design, development, testing, implementation, and maintenance, in order to ensure that business and application knowledge repositories remain in one location.

Table 1 provides an analytical summary of the Telecon case.

\subsection{Case study 2-content tagging for Webmarkets}

Webmarkets, Inc. is a 13 years old, privately held organization that provides institutional clients and

Table 1

Coordination mechanisms and outcomes in the Telecon case

\begin{tabular}{|c|c|c|c|}
\hline Phase & $\begin{array}{l}\text { Task specification/partitioning } \\
\text { techniques }\end{array}$ & Integration mechanisms & Outcomes \\
\hline $\begin{array}{l}\text { Onshore } \\
\text { outsourcing }\end{array}$ & $\begin{array}{l}\text { Prospera's grouping of Telecon's } \\
\text { applications using "application } \\
\text { constellations"; Prospera's use of } \\
\text { CMM Level } 4 \text { software processes }\end{array}$ & $\begin{array}{l}\text { Transfer of } 1200 \text { Telecon employees to } \\
\text { Prospera; dedicated multi-tier Telecon } \\
\text { structure for interfacing with Prospera }\end{array}$ & $\begin{array}{l}\text { Success; improvements in } \\
\text { adherence to time and budget } \\
\text { goals; better project completion } \\
\text { rates; reduced development and } \\
\text { support costs; cutting edge } \\
\text { applications and solutions }\end{array}$ \\
\hline $\begin{array}{l}\text { Pilot } \\
\text { offshoring }\end{array}$ & $\begin{array}{l}\text { Offshoring limited to highly structured } \\
\text { production tasks; carefully selected pilot } \\
\text { applications based on task criteria such } \\
\text { as complexity and stability }\end{array}$ & $\begin{array}{l}\text { Visits by offshore application teams to } \\
\text { Prospera's onshore site for effecting } \\
\text { transfer of business and technological } \\
\text { knowledge }\end{array}$ & $\begin{array}{l}\text { Questionable success; Telecon's } \\
\text { abandonment of formal offshoring } \\
\text { resource review due to cost pressures; } \\
\text { Telecon's urgency led to it being } \\
\text { dismissive of problems and issues; } \\
\text { Prospera went along with Telecon; } \\
\text { no dramatic pilot failures }\end{array}$ \\
\hline $\begin{array}{l}\text { Full-blown } \\
\text { offshoring }\end{array}$ & $\begin{array}{l}\text { Prospera did not apply its "global } \\
\text { delivery model" for specifying, } \\
\text { splitting up, and distributing tasks; } \\
\text { task specification/partitioning } \\
\text { assumed on grounds that } \\
\text { back-office applications signify } \\
\text { well-defined tasks, standardized } \\
\text { business processes }\end{array}$ & $\begin{array}{l}\text { Prospera's hybrid offshoring model } \\
\text { provided for both onshore and offshore } \\
\text { staff, with built-in liaison and interface } \\
\text { roles; visits by offshore application } \\
\text { teams to Prospera's onshore site }\end{array}$ & $\begin{array}{l}\text { Failure; scarce documentation created } \\
\text { need for frequent, intense onshore- } \\
\text { offshore interactions, leading to reduced } \\
\text { productivity; internal and external } \\
\text { dynamics caused attrition of key } \\
\text { personnel at both ends; offshoring } \\
\text { scale increased by Telecon and } \\
\text { Prospera even as onshore-offshore } \\
\text { communication failed; fines levied by } \\
\text { Telecon on Prospera for non- } \\
\text { performance; Prospera responded by } \\
\text { reorganizing offshore staff but this } \\
\text { created "ownership" issues }\end{array}$ \\
\hline
\end{tabular}


analysts with timely, market-sensitive online business intelligence, pertaining to markets in Asia, Latin America, Eastern Europe, and Central Europe. Its New York headquarters is responsible for all products and services, and various country-specific offices for local sales. Originally setup to gather business intelligence out of Eastern Europe, Webmarkets gradually expanded and was eventually acquired in the late 1990s by a Europe-based financial research publisher. Now comprising of about 250 employees and grossing about US\$20 million in sales, Webmarkets is a niche leader, witnessing tremendous growth of its existing and new information services.

Webmarkets' experience with offshoring has involved about a dozen projects altogether over the past 7 years, ranging in value from US\$100,000 to 400,000 . Most projects pertain to the tagging of news content, a common task in the media and publishing industry. Essentially, items coming off a raw news feed or data source need to be processed to make them more useful to the end user. This entails ascribing multiple labels to items, thereby enhancing users' ability to search and categorize them.

Offshoring began around 1999, when Webmarkets hired a small, independent offshore vendor to complete a couple of minor projects over the course of about a year. Both projects went reasonably well as assessed in terms of their major direct outcomes, which were lowered content tagging costs. However, the overall offshoring experience turned out to be a bumpy road for both parties. From Webmarkets' perspective, the vendor demonstrated an inability to work independently and was unresponsive, despite having been carefully selected from a list of potential service providers. From the vendor's point of view, the client was not available to provide guidance when needed, yet expected timely service. Relations quickly got strained to the point of being beyond repair.

Since the projects did yield cost savings, Webmarkets decided to scale up its offshoring initiative after their completion. However, as going back to the original vendor was not feasible, other alternatives were identified. One option was to switch to a bigger, more reputable vendor. Doing so would have likely provided a more stable experience, but after careful consideration Webmarkets decided that the best way to carry its offshoring momentum forward would be to have a captive service provider of its own, located overseas.

In accordance with this vision, Webmarkets established a new offshore data services group comprising of carefully screened technology professionals in 2001 . This unit was setup to be an independently run and operated subsidiary of Webmarkets' Europe-based parent company. In order to fully leverage the investment undertaken in establishing the offshore subsidiary, several personnel teams at the New York headquarters were disbanded, and various independent consultants who assisted them were let go or reassigned to other tasks. Most importantly, this time around Webmarkets duly applied the valuable lessons it had learned on the risks of inter-organizational relationships and the structure of offshored tasks. This prevented it from repeating the problems it had faced with the first vendor, and ensured that the cost savings gained from onshore-offshore wage disparities would not be offset by excessive coordination costs.

Webmarkets' successes with small content tagging projects emboldened it to send bigger projects to its offshore captive subsidiary over the next few years. Aside from some minor setbacks, the content tagging successes were replicated repeatedly, the offshore team continued to grow, and Webmarkets kept pushing out more work to it. Unlike classic development projects, Webmarkets' development projects represent ongoing endeavors in tagging and classification, and all eight continue successfully to this day, as measured by both objective criteria and client satisfaction. Some recent work has evolved from development into the operations arena.

The primary benefit to Webmarkets from offshoring has been reduced, and more predictable, development costs. It has been able to cut its headcount in the U.S. and in other high wage regions such as Europe. Another important benefit is a renewed ability to focus on their core business and technology competencies. Now that the operational and development burdens have been lifted off the shoulders of the in-house information technology staff, they are freer to focus on identifying new technologies, as well as understanding, evaluating, and selecting them. This, in turn, moves the business forward faster.

\subsection{Coordination mechanisms and outcomes in the Webmarkets case}

The effectiveness of the coordination mechanisms employed by Webmarkets will now be assessed for each of the two distinct phases in the case. In the first phase, Webmarkets' underdeveloped coordination mechanisms to support its interactions with the independent overseas vendor yielded disastrous outcomes. In the second phase, the corrective actions it undertook on both task and integration fronts with the captive vendor led to unqualified success. The following discussion will demonstrate how Webmarkets went from a failure 
in the small first phase to a success in the larger second phase, representing an opposite direction of outcomes from that of Telecon.

\subsubsection{Independent vendor}

While Webmarkets did not give actively address task specification and partitioning in this first phase, it took both into account. Since the publishing industry does not agree on a common content tagging system, Webmarkets has developed its own system which utilizes a universal tag set. Tags are applied to specific content by a proprietary combination of manual methods and automated mechanisms that encompass artificial intelligence-based classification techniques. As the primary objective was reduced costs, manual tagging processes comprising of highly structured, labor-intensive activities were considered by Webmarkets as prime candidates for initial offshoring endeavors.

Integration mechanisms were also indirectly addressed in this phase. Given a plethora of tagging standards, Webmarkets' had looked for an offshore vendor who not only possessed content tagging skills and experience but whose standards and approach to the tagging process closely resembled its own. Accordingly, several independent vendors had been identified, vetted, and short listed based on these criteria, before settling on this "similar thinking" vendor. This selection process demonstrated Webmarkets' awareness of integration issues.

However, when it came to actually implementing inter-organizational integration mechanisms, Webmarkets' displayed a considerable lack of foresight. Instead of setting up the vendor to report directly to the New York headquarters responsible for product development and management, it was made to report to the local Webmarkets office responsible for sales. This created a communication disconnect between the vendor and the New York-based technology group. The resulting divide was compounded by a gap between client expectations and reality. The technology group expected the vendor to work independently with minimal day-to-day supervision, as it considered the work to be highly structured, entailing very little uncertainty. This expectation was consistent with Webmarkets' offshoring goals of cost savings through a reduced head count at headquarters. In reality, the indirect linkages between client and vendor via the offshore Webmarkets office created unforeseen coordination and control issues. Occasionally, these issues would spin out of control, necessitating unplanned overseas trips on the part of New York staff for intervention and troubleshooting. The situation was exacerbated by a high demand for the vendor's well-regarded services from its numerous other clients, which prevented it from providing the service levels desired by the technology group. At one point, this demand transformed into a lucrative sale opportunity for the owner of the vendor organization. A change in ownership and management resulted, together with a predictable turnover of vendor personnel.

\subsubsection{Captive vendor}

Stung by its poor integration experiences in the first phase, Webmarkets concluded that offshoring coordination issues would best be mitigated through the use of a captive vendor. Its rationale was that a captive vendor organization could be more easily positioned to be answerable directly to headquarters rather than the offshore country office. While it would operate overseas as a separate entity, the client group could count on it to operate by its own rules and timelines, and even have a stake in the vendor's personnel decisions. The higher level of control over a captive vendor would enable Webmarkets to tailor the vendor's processes in consonance with its own objectives, and to confidently escalate offshored work as and when needed. Although a captive vendor would need other clients in order to maintain profitability, higher priority would be accorded to work flowing in from Webmarkets.

Redesigning its integration mechanisms to make them more effective was thus the foremost concern for Webmarkets in the second phase. Further, the vendor's status as a subsidiary of the Europe-based parent company rather than Webmarkets meant that the latter could achieve the requisite degree of operational control without the corresponding financial responsibility, a best of both worlds scenario. The parent company's gain from this arrangement was as an investment in a growth business, thus representing a win-win solution for both itself and Webmarkets.

Webmarkets' also amended its approach to task specification and partitioning in the second phase. It had learned from experience that offshored work presented a higher risk of failure if it called for repeated, iterative client-vendor interactions. To lower this risk (despite the fact that a captive vendor inherently offered less of a risk), ongoing projects were restructured to the extent possible and divided up into two types of activities. The first type required industry and domain knowledge, and entailed creative processes calling for higher level skills. The second called for little or no domain knowledge, and could be completed by following a well-documented series of steps. Examples of the former kind of work were technology evaluation and selection, testing new technologies or ideas for new information services, 
and general decision-making activities. These would be isolated and retained in-house. The second category, consisting of work that could be easily offshored, essentially entailed applying documented processes and standards to tag content. The second category could also include work that the home team did not consider to be worth their time. For instance, on one occasion when an elite onshore team was in the midst of evaluating a new set of search technology tools, something even more promising arrived in the market. A team of competent offshore personnel was setup to take over the testing process so that the onshore technology staff could focus on the next frontier of search tools.

To ensure consistency of the offshored work and to minimize wasteful, repetitive iterations with the vendor, Webmarkets tightened all of its application and infrastructure specifications, including platforms, databases, programming languages, server processes, coding standards, and documentation standards. This all but eliminated the need for collaborative work and day-to-day interdependence between vendor and client. Offshore visits by onshore staff became more proactive in nature, e.g., to cross-train personnel. Onshore architects and managers continually monitored the progress of offshored work using project management tools, and quality assurance experts regularly conducted evaluations of completed work. In addition, all work completed offshore was first staged and tested in experimental mode, before being ported to final production.

These changes led to successful project experiences with the captive vendor. The next step in Webmarkets'

Table 2

Coordination mechanisms and outcomes in the Webmarkets case

\begin{tabular}{lll}
\hline Phase & $\begin{array}{l}\text { Task specification/partitioning } \\
\text { techniques }\end{array}$ & Integration mechanisms \\
\hline $\begin{array}{l}\text { Independent } \\
\text { offshore vendor }\end{array}$ & $\begin{array}{l}\text { Offshoring limited to manual } \\
\text { tagging processes comprising of } \\
\text { structured, labor-intensive } \\
\text { activities }\end{array}$ & $\begin{array}{l}\text { Indirect, via careful identification of } \\
\text { vendor whose standards and approach } \\
\text { to the content tagging process were } \\
\text { compatible with those of Webmarkets }\end{array}$
\end{tabular}

Outcomes

Failure; vendor setup to report to offshore sales office rather than to onshore client group; indirect vendor-client linkages created coordination, control, and communication problems; unplanned overseas trips by onshore staff for intervention and problem resolution; further deterioration in service due to high demand for vendor's services from other clients; change in vendor management led to personnel attrition and compounded problems

\section{Captive offshore vendor}

\author{
Ongoing Webmarkets projects \\ restructured and split up. Tasks \\ calling for industry/domain \\ knowledge, or requiring creative, \\ discretionary skills, retained \\ in-house. Tasks were offshored if \\ they could be completed by \\ following well-documented steps, \\ or if they were overflow work; \\ application- and infrastructure- \\ related specs tightened to reduce \\ client-vendor interdependence \\ and need for collaboration; \\ project management and quality \\ assurance retained in-house; \\ work completed offshore staged \\ and tested in experimental \\ mode before being put into \\ production
}

Webmarkets established captive offshore service provider to exercise greater control and achieve better coordination, by tailoring vendor's processes in consonance with its own objectives; vendor operationally positioned to interface directly with onshore client; financial responsibility for vendor circumvented through vendor placement under Webmarkets' holding company in organizational chart; priority system accorded greater importance to Webmarkets' work and facilitated more stable relationship, given high demand for vendor services and personnel churn; shift in nature of overseas trips by headquarters staff, from reactive interventions to proactive bridging mechanisms such as cross-training programs
Success; accurate tagging of news content; cost savings through headcount reduction and faster turnaround times; greater predictability and evenness of development costs; gradual increase in complexity of offshored development and database work; renewed ability to focus internally on business and technological competencies 
offshoring evolution was to gradually increase project complexity such that new projects involved some custom coding in addition to tagging content. As these newer projects also yielded continued successes, the work sent overseas metamorphosed into a full-blown development and operational environment, including the setup and maintenance of applications and databases. Full staffing for the vendor organization was achieved around 2004, but steady states in the understanding and flawless execution of client needs had been reached long before that.

Table 2 provides an analytical summary of the Webmarkets case.

\section{Implications}

It would be useful to first review the key contextual differences between the two case studies before delving into their implications for managing offshored software tasks. One such difference is in terms of the affiliations of, and relationships between, the interacting onshoreoffshore teams. The Telecon case describes interactions between a consultant vendor's offshore team and its client-facing onshore team. On the other hand, the Webmarkets case is a study in progressive interactions between an onshore client and its successive offshore vendors, the first relationship being contractual in nature and the second an inter-organizational hierarchy. Another key difference lies in the nature of offshored tasks. Telecon's offshored tasks began with the development of front- and back-office applications, and subsequently transitioned into the enhancement and maintenance work for these applications. Webmarkets' offshored tasks primarily comprised of simple, structured, technology-enabled services such as document conversion and knowledge management. These were later accompanied by applications development and enhancement, representing a somewhat higher degree of complexity.

Despite these foremost differences in context, there are overarching commonalities in the lessons that may be distilled from the successful and unsuccessful approaches followed by Telecon and Webmarkets. The presence of contextual differences in fact serves to amplify the validity of these common lessons. The first such lesson is that a generally well structured but composite task does not necessarily comprise a ripe candidate for offshoring. An imperative is to analyze the constituent sub-tasks, in order to isolate the inherently more structured, less discretionary, and loosely coupled components from the more creative, more discretionary, and more interdependent ones. Activities in the former set make for more natural offshoring candidates. The latter are best retained in-house, or, if offshored, at the very least call for much greater joint client-vendor attention in the planning and setup stages. Webmarkets' sequential interactions with its two vendors particularly highlight this point. With the first vendor, Webmarkets' rationale was that since the manual aspect of content tagging was labor intensive as well as generally well structured, it must therefore be ideal for fully contracting out. With this logic, considerable effort was even made to identify a vendor whose business practices and processes were similar to those of the client. Missing from this equation, however, was an effort to assess the individual activities that made up the content tagging task, to chart their attributes and trace any interdependencies, and to use this information as the basis for apportioning specific tasks to the vendor and client. Tasks assigned to the vendor would need to be more granular, thoroughly specified, and loosely coupled with tasks for which the client was responsible, thus reducing coordination costs and risks that might lead to failure. This negligence was duly rectified in Webmarkets' subsequent offshoring interactions with its captive vendor. With this second vendor, an approach akin to "vertical chunkification" was followed [4]. The overall process was divided up into sequential, nonoverlapping, relatively independent parts or chunks of activities that could be separated from the rest, thereby reducing the extent of knowledge transfer required from client to vendor, and therefore the risk associated with offshoring the entire process as a single entity.

A related implication may be drawn from the Telecon case. Even when due care is taken to break a composite task down into smaller sub-tasks, the more structured components of the original task do not necessarily make for ideal offshoring candidates. Whether or not they are apt for offshoring also depends on how interdependent these components are with the other sub-tasks. Tightly integrated sub-tasks are less separable for processing from each other, and also more difficult to monitor. A large empirical study focusing on knowledge-oriented tasks assigned to employees and contractual co-workers at an aerospace company found that organizations tend to assign the interdependent types of tasks to employees so that contractors can be given more independent tasks that can be easily monitored, thus reducing organizational dependence on contractors [24]. Another study of pharmaceutical firms revealed that client organizations assign knowledge-intensive clinical trials to internal teams, but dataintensive tasks that are easily monitored are more often outsourced [5]. Telecon and its vendor, Prospera, 
seemed to understand that the entire development life cycle of applications analysis, design, coding, maintenance, and operations constituted too big a task and represented too large a risk. The vendor therefore suggested that the offshored components be limited to the more structured and less discretionary tasks of enhancement and maintenance, and Telecon concurred. While this logic obviously accorded due consideration to task size and structure, it did not factor in the potential interdependencies among related sub-tasks. For various reasons including incomplete contextual knowledge, post-production support turned out to be fairly tightly coupled with design and coding, the latter two being activities that had not been offshored. This tight coupling led to the need for closer onshoreoffshore coordination than what had been put in place.

Another lesson pertains to the position of the offshored task in the overall sequence of related activities. Relative to tasks that occur earlier in the development lifecycle sequence (e.g., component coding), whose output and quality are more amenable to being controlled and assured by the client, tasks such as maintenance and support that occur later in the sequence leave less control in the client's hands. In the Telecon case, the offshore site's failure to meet minimum client service levels represented an undesirable end point from where no backtracking, corrective action, or damage control of any kind was possible. This led to the automatic imposition of non-performance penalties by the client on the vendor. Agency theory provides a validation of this lesson, in the context of firms that require upstream and downstream tasks to be completed, of which one at least one task must be outsourced to an outside supplier. Using appropriate theoretical assumptions, mathematical derivations show that it would be in the best interests of the principal (i.e., the client) to assign the upstream task more often to the supplier, and the downstream task more often internally [28]. The clear implication of this in the offshoring context is that among sequentially interdependent tasks, those occurring earlier in the chain have a greater likelihood of success if offshored, since this would enable greater control over the final product to be retained in house. The Webmarkets case provides empirical support for this notion. With the second vendor, the client's decisions to retain the quality assurance function in-house and to experimentally stage and test all completed work before putting into production ensured that the client maintained control of the downstream tasks. This meant that Webmarkets retained the final say on whether tasks that were supposedly complete actually made it to the production stage, resulting in positive outcomes that were quite in marked contrast to Telecon's disastrous ones.

The key lesson with respect to integrative mechanisms from both case studies is that the structuring, specification, and partitioning of offshored tasks needs to be conceptualized and implemented in congruence and harmony with the design of integrative, bridging mechanisms between client and vendor. These two aspects of procedural coordination are complementary or synergistic, and an insufficient attention to either represents an imbalanced approach likely to result in project failure. Both case studies exemplify this. For Telecon, offshored tasks in the pilot phase comprised of stable, well-structured, back-office applications of low complexity and impact. The careful selection of tasks was duly accompanied by an effort to bridge any gaps in contextual and application-specific knowledge between the onshore and offshore locations. This was done by instituting offshore application teams, placing offshore liaisons at the onshore vendor site for extended periods of time, and putting in place policies and procedures to ensure compatibility with the client's technological standards and business processes. Compatible efforts on these twin fronts facilitated the smooth progress of the pilot project. In contrast, the full-blown offshoring phase saw a relaxation of task selection standards, as vastly greater numbers of applications with increasingly interdependent attributes were roped in for offshoring. Congruence called for a simultaneous significant intensification of the integrative mechanisms, to account for these relaxed task standards. Instead, they were deemed adequate and left unchanged, largely due to a poor understanding of local staff constraints and markets dynamics at both onshore and offshore ends. This resulted in insufficient sharing of contextual knowledge, which undermined the utility of these mechanisms and ultimately rendered them totally ineffective. Telecon's near classic coordination failure is evocative of a research study of virtual teams with cultural and organizational differences among its members, which found that members of such teams often fail to share information about local contexts, constraints, and tasks, and that this ultimately prevents effective coordination [9].

Webmarkets' interactions with its two vendors took an opposite direction. The interaction transitioned from an initially ineffective approach with the first vendor to an ultimately effective approach with the second. In dealing with the first vendor, Webmarkets addressed both task attributes and integration mechanisms, but did so partially and rather independently of each other. With respect to task, it took heed of the fact that the overall 
task was well structured, but overlooked its partitioning aspect. With respect to integration mechanisms, Webmarkets was cognizant of the need for working with a vendor whose processes and procedures mirrored its own, but erred in setting it up so that the vendor reported to a local sales office rather than the distant development client. The net result was an offshored task that required frequent client-vendor interactions of considerable intensity, but contextually situated in an incompatible environment where the client neither wanted nor expected them, nor possessed any effective channels to cope with them. Webmarkets duly applied the lesson learned in setting up arrangements with the second vendor. This time around, the vendor was assigned task components that were highly structured and tightly specified in terms of both the work and the tools to be used, required little or no domain knowledge, were non-discretionary in nature, and could be completed independently of other components. Simultaneously, effective communication and integration between client and vendor was ensured through the establishment of a hierarchical structure, cross-training programs, quality assurance processes, and the application of project management principles.

The critical role that integrative communication mechanisms play in binding globally dispersed teams is underscored by a research study that analyzed the dynamics of such teams using adaptive structuration theory [22]. A key conclusion was that under conditions of high task interdependence and complexity, such teams can only be effective if their communication mechanisms keep up, both in terms of interactions as well as their richness and level of decision processes. The significance of mutual adjustment and communication to alleviate problems stemming from interdependence has also been noted elsewhere, both in the context of software development [1,25], as well as in general information processing theories [11,12].

\section{References}

[1] P.S. Adler, The evolving object of software development, Organization 12 (3), 2005, pp. 401-435.

[2] E.R. Alexander, A structuration theory of interorganizational coordination: cases in environmental management, The International Journal of Organizational Analysis 6 (4), 1998, pp. 334354.

[3] H.P. Andres, R.W. Zmud, A contingency approach to software project coordination, Journal of Management Information Systems 18 (3), 2001, pp. 41-70.

[4] R. Aron, E.K. Clemons, S. Reddi, Just right outsourcing: understanding and managing risk, Journal of Management Information Systems 22 (2), 2005, pp. 37-55.
[5] P. Azoulay, Capturing knowledge within and across firm boundaries: evidence from clinical development, The American Economic Review 94 (5), 2004, pp. 1591-1612.

[6] E. Beulen, P.V. Fenema, W. Currie, From application outsourcing to infrastructure management: extending the offshore outsourcing service portfolio, European Management Journal 33 (2), 2005, pp. 133-144.

[7] S.J. Carson, A. Madhok, R. Varman, G. John, Information processing moderators of the effectiveness of trust-based governance in interfirm R\&D collaboration, Organization Science 14 (1), 2003, pp. 45-56.

[8] I.S. Chung, Y.R. Kwon, An approach to partitioning programs on the functional basis and applications, Microprocessing and Microprogramming 40 (5), 1994, pp. 315-326.

[9] C.D. Cramton, The mutual knowledge problem and its consequences for dispersed collaboration, Organization Science 12 (3), 2001, pp. 346-371.

[10] C.D. Cramton, S.S. Webber, Relationships among geographic dispersion, team processes, and effectiveness in software development work teams, Journal of Business Research 58 (6), 2005, pp. 758-765.

[11] R.L. Daft, R.H. Lengel, Information richness: a new approach to managerial behavior and organization design, in: L.L. Cummings, B.M. Staw (Eds.), Research in Organizational Behavior, (vol. 6), JAI Press, Greenwich, CT, 1984, pp. 191233.

[12] R.L. Daft, R.H. Lengel, Organizational information requirements, media richness, and structural design, Management Science 32 (5), 1986, pp. 554-571.

[13] S. Globerman, A.R. Vining, A framework for evaluating the government contracting-out decision with an application to information technology, Public Administration Review 56 (6), 1996, pp. 577-584.

[14] Anna Grandori, An organizational assessment of interfirm coordination modes, Organization Studies 18 (6), 1997, pp. 897-925.

[15] R. Gulati, P.R. Lawrence, P. Puranam, Adaptation in vertical relationships: beyond incentive conflict, Strategic Management Journal 26 (5), 2005, pp. 415-440.

[16] L. Hakanson, Managing cooperative research and development: partner selection and contract design, R\&D Management 23 (4), 1993, pp. 273-285.

[17] D.E. Harter, S.A. Slaughter, Quality improvement and infrastructure activity costs in software development: a longitudinal analysis, Management Science 49 (6), 2003, pp. 784-800.

[18] J.B. Heide, A.S. Miner, The shadow of the future: effects of anticipated interaction and frequency of contact on buyer-seller cooperation, Academy of Management Journal 35 (2), 1992, pp. 265-291.

[19] M. Hoegl, K.P. Parboteeah, H.G. Gemuenden, When teamwork really matters: task innovativeness as a moderator of the teamwork-performance relationship in software development projects, Journal of Engineering and Technology Management 20 (4), 2003, pp. 281-302.

[20] R.T. Keller, Technology-information processing fit and the performance of R\&D project groups: a test of contingency theory, Academy of Management Journal 37 (1), 1994, pp. 167-179.

[21] K.K. Kim, N.S. Umanath, Structure and perceived effectiveness of software development subunits: a task contingency analysis, Journal of Management Information Systems 9 (3), 1992, pp. $\underline{157-181 .}$ 
[22] M.L. Maznevski, K.M. Chudoba, Bridging space over time: global virtual team dynamics and effectiveness, Organization Science 11 (5), 2000, pp. 473-508.

[23] S.M. Miranda, C.B. Kavan, Moments of governance in IS outsourcing: conceptualizing effects of contracts on value capture and creation, Journal of Information Technology 20 (3), 2005, pp. 152-169.

[24] J.L. Pearce, Toward an organizational behavior of contract laborers: their psychological involvement and effects on employee co-workers, Academy of Management Journal 36 (5), 1993, pp. 1082-1096.

[25] D. Robey, R. Welke, D. Turk, Traditional, iterative, and component-based development: a social analysis of software development paradigms, Information Technology and Management 2 (1), 2001, pp. 53-70.

[26] M. Sobrero, E.B. Roberts, The trade-off between efficiency and learning in interorganizational relationships for product development, Management Science 47 (4), 2001, pp. 493-511.
[27] M. Sobrero, S. Schrader, Structuring inter-firm relationships: a meta-analytic approach, Organization Studies 19 (4), 1998, pp. 585-615.

[28] S.S. Sridhar, B.V. Balachandran, Incomplete information, task assignment, and managerial control systems, Management Science 43 (6), 1997, pp. 764-778.

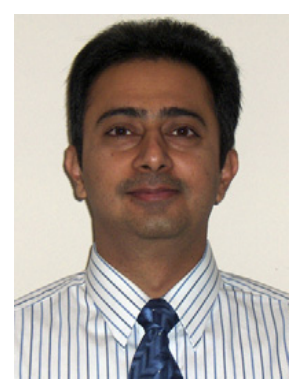

Rajesh Mirani is associate professor of information systems at the Merrick School of Business, University of Baltimore. He holds a PhD from the University of Pittsburgh. His research interests are generally oriented around the broad issue of business and information systems alignment. His present focus is on how organizations manage their offshoring endeavors. He has previously published in Decision Sciences, Journal of MIS, and MIS Quarterly, among other journals. 